\title{
Learning to swim: role of gender, age and practice in Latino children, ages 3-14
}

\author{
Rho Henry Olaisen, ${ }^{1,2}$ Susan Flocke, ${ }^{1,3}$ Thomas Love ${ }^{1,4}$
}

- Additional material is published online only. To view please visit the journal online (http://dx.doi.org/10.1136/ injuryprev-2016-042171).

${ }^{1}$ Department of Epidemiology and Biostatistics, Case Western Reserve University School of Medicine, Cleveland, Ohio, USA ${ }^{2}$ Department of Population Health and Outcomes Research Core-CTSC, Case Western Reserve University School of Medicine, Cleveland, Ohio, USA ${ }^{3}$ Department of Family Medicine and Community Health, Case Western Reserve University, Cleveland, Ohio, USA

${ }^{4}$ Better Health Partnership, Cleveland, Ohio, USA

\section{Correspondence to} Rho Henry Olaisen, Department of Epidemiology and Biostatistics, Case Western Reserve University School of Medicine, 10900 Euclid Ave, Cleveland, $\mathrm{OH}$ 44106-4915, USA; rho2@case.edu

Received 27 July 2016 Revised 14 February 2017 Accepted 28 March 2017 Published Online First 26 April 2017
Check for updates

To cite: Olaisen $\mathrm{RH}$, Flocke $\mathrm{S}$, Love T. Inj Prev 2018;24:129-134.

\section{ABSTRACT}

Objective We evaluate the effectiveness of a swim skill acquisition intervention among Latino youths, ages 3-14, a minority population at increased risk of drowning.

Methods Parents were recruited through community institutions to have their children participate in group swim lessons. Each child's swim ability was assessed at baseline, and they were then exposed to swim lessons over an 8-week period, taught by trained professionals. The swim skill curriculum focused on water safety, flotation and endurance, at five levels of increasing skill acquisition. Final swim ability was assessed on the last day of the child's participation. Programme effectiveness was measured using direct pre-post comparisons with and without adjustment for key moderators (age and gender) and a mediator (number of practices). We also present a bias-adjusted estimate comparing low with high practice volume relying on a propensity score analysis.

Results Among the 149 participating children, average acquisition was 12.3 swim skills $(95 \% \mathrm{Cl} 10.7$ to 14.1$)$. Skill acquisition varied by age category $(3-5,6-9$ and 10-14 years) and by gender. We found a strong practice intensity effect, with skill acquisition accelerated for those participating in 10 or more swimming lessons. The propensity-adjusted estimate of the impact of 10 or more compared with 9 or fewer lessons was 8.2 skills (95\% Cl 4.8 to 11.8 ).

Conclusions An 8-week swim intervention is effective at building skills in a community-based sample of Latino children, ages 3-14 years. The number of swimming lessons was a far stronger correlate of skill acquisition than were age or gender.

\section{INTRODUCTION}

Drowning is the leading cause of death for children ages 1-4 and the second leading cause of death for children ages $5-14$ in the USA. ${ }^{1}$ Drowning is the process of experiencing respiratory impairment from submersion/immersion in water, leading to death or non-fatal events with or without complications. For every death due to drowning, twice as many non-fatal events resulting from drowning are treated in emergency rooms. ${ }^{1}$ For children $(0-14)$ who experience drowning, swimming pools are the most common setting (47\%), followed by natural bodies of water $(25 \%)$, boating accidents (15\%) and bathtubs (13\%). ${ }^{2}$

Drowning outcomes show pronounced health disparities in terms of race, gender, age, socioeconomic status and physical setting. African American, Native American and Latino children are at two to eight times greater risk of drowning resulting in death compared with their white counterparts, ${ }^{3-8}$ with likely under-reporting of mortality relating to Latinos, who are often classified as white on death certificates. White children die disproportionately in home pools, while African American and Latino children more often drown in community pools. ${ }^{15}$ Boys from the ages of 5-14 are at particularly high risk of drowning resulting in death. ${ }^{9}$ While African Americans' lower level of swimming skills relative to whites have been reliably documented, ${ }^{1}{ }^{2}$ less is known about the level of swimming skills of Latino children. ${ }^{10} 11$ The rapidly expanding Latino segment of the US population, in combination with the substantially greater risk of drowning resulting in death among Latino children, points to a potentially growing problem in this regard if left unaddressed.

The incidence of drowning has in recent years been determined to be in slight decline in the USA (from 1.34 in 2005 to 1.25 per 100000 in 2009), although this does not take into account the demographic trend mentioned immediately above. To reduce drowning rates by $10 \%$ to $1.1 \%$ per 100000 by 2020, a goal set by the Office of Disease Prevention and Health Promotion, expansion of evidence-based programmes in conjunction with system changes is recommended. ${ }^{12}$ Recent studies have suggested that drowning can be effectively reduced through evidence-based water safety programmes, including swimming lessons and health education. ${ }^{13}{ }^{14}$ Knowing how to swim is a life-saving skill, with instruction particularly needed for minority populations, which have traditionally been neglected in this regard.

Although there is little dispute that swimming instruction can build skills that may avert drowning, ${ }^{1} 21215$ there is uncertainty about the specific effects of particular interventions, as well as differences in the effectiveness of interventions by age and gender. There is also uncertainty as to what minimal amount of instruction will have measurable results. As community health interventions do not easily lend themselves to randomised controlled trials, we designed an observational study with the primary objective of measuring the relationship of age, gender and number of swimming lessons on skill acquisition by Latino immigrant children.

\section{METHODS}

This was an intervention study involving 149 children (age 3-14) who participated in an 8-week swimming lesson intervention between June and August 2014 held at the Hoover community pool in Redwood City, California, a municipal-owned facility, approximately $50 \mathrm{~km}$ south of San Francisco. Participants were recruited from five community 
organisations within the immediate area of the intervention, a low-income neighbourhood with a predominantly Latino population.

\section{Inclusion/exclusion}

We recruited parents of young children to health education sessions through collaboration with neighbourhood community organisations. Parents attended one of six $45 \mathrm{~min}$ interactive health education seminars delivered in Spanish by trained health educators, drawing upon evidence-based best practices ${ }^{15} 16$ and risk factors associated with drowning. ${ }^{15} \quad 17{ }^{18}$ All attending parents were encouraged to register their children ages 3-14 for complimentary swim assessments held at the intervention site. All the children of those parents were allowed to participate in the learn-to-swim intervention. No child was refused participation in the community intervention, regardless of residence location, race or disability status. Although the programme recruited a total of 395 children, for purposes of this analysis, we restricted eligibility criteria to those children ages 3-14, with no known disability, Latino ethnicity, living within the lowincome census tracts of the pool, who spoke Spanish at home, for which there existed complete survey data for both parents and child, and cases with at least baseline and follow-up assessment. Latino ethnicity was determined by self-report from an in-person survey tool.

\section{Conceptual model}

Our conceptual model (see figure 1) was informed by the Health Belief Model ${ }^{19}$ and a socialecological framework. ${ }^{20}$ The health belief model posits that a person is more likely to implement a behavioural change when faced with a threat perceived as avoidable. The health belief model also posits that the behavioural change must be perceived as attainable and have protective qualities. ${ }^{19}$ Following a socialecological framework, we identified individual, familial and community factors known or believed to influence participation in swim interventions (see complete list of items in table 1). Our conceptual model presumes that the relationship between swimming lessons and prepost change in swim skills (hereafter 'skill acquisition') is

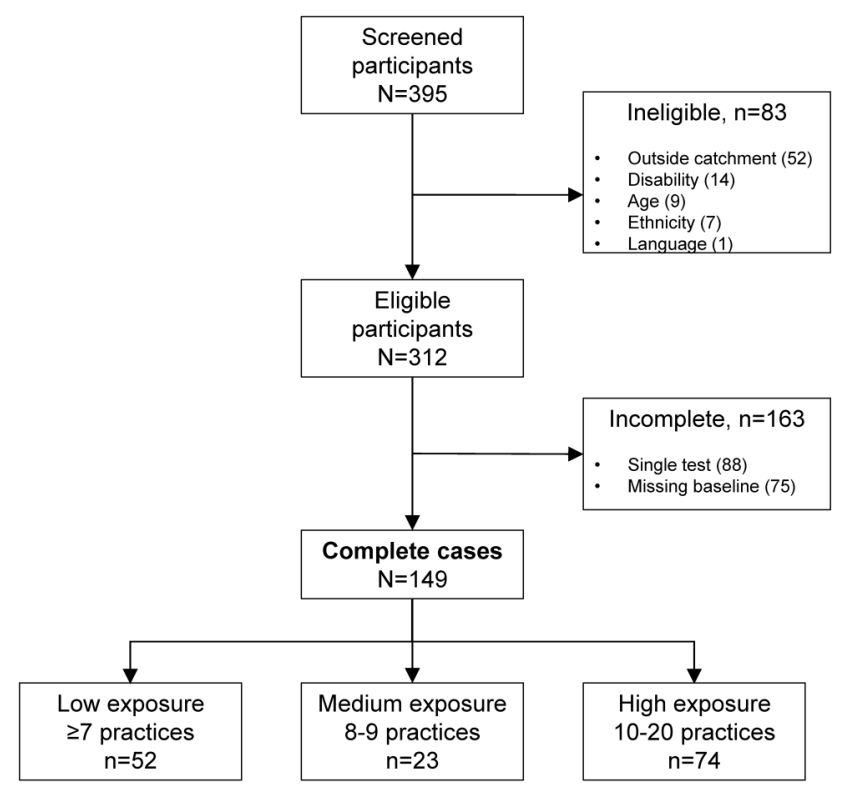

Figure 1 Inclusion-exclusion tree, Hoover community learn-to-swim evaluation. influenced by age, gender and number of swimming lessons, with a greater number of swimming lessons leading to a higher level of skill acquisition.

\section{Intervention}

We engaged parents to sign children up for the intervention. Parents were recruited to participate in a 45 min educational presentation/slideshow relating to water safety and drowning, followed by a $15 \mathrm{~min}$ question-and-answer session, facilitated in Spanish by two health educators. Childcare was available at no cost. After the parent intervention, an 8-week learn-to-swim

Table 1 Baseline characteristics

\begin{tabular}{|c|c|c|c|}
\hline Baseline characteristic & $\begin{array}{l}\text { Girls } \\
n=83\end{array}$ & $\begin{array}{l}\text { Boys } \\
\mathrm{n}=66\end{array}$ & $\mathrm{p}$ Value \\
\hline Age (mean (SD)) & $7.62(2.66)$ & $8.02(2.60)$ & 0.36 \\
\hline Age groups (\%) (years) & & & 0.87 \\
\hline $3-5$ & $26(31.3)$ & $18(27.3)$ & \\
\hline $6-9$ & $38(45.8)$ & $32(48.5)$ & \\
\hline $10-14$ & $19(22.9)$ & $16(24.2)$ & \\
\hline Child has had formal swim lessons (\%) & $10(12.0)$ & $6(9.1)$ & 0.75 \\
\hline \multicolumn{3}{|c|}{ Child was exposed to ocean last 12 months (\%) } & 0.09 \\
\hline None & $34(41.0)$ & $39(59.1)$ & \\
\hline $1-5$ times & $43(51.8)$ & $23(34.8)$ & \\
\hline $6+$ & $6(7.2)$ & $4(6.1)$ & \\
\hline \multicolumn{3}{|c|}{ Child was exposed to lake last 12 months (\%) } & 0.09 \\
\hline None & $24(28.9)$ & $29(43.9)$ & \\
\hline $1-5$ times & $55(66.3)$ & $32(48.5)$ & \\
\hline $6+$ & $4(4.8)$ & $5(7.6)$ & \\
\hline \multicolumn{3}{|c|}{ How comfortable is child placing head under water? (\%) } & 0.45 \\
\hline Very uncomfortable & $49(59.0)$ & $42(63.6)$ & \\
\hline A little & $10(12.0)$ & $6(9.1)$ & \\
\hline Neutral & $14(16.9)$ & $14(21.2)$ & \\
\hline Somewhat & $4(4.8)$ & $2(3.0)$ & \\
\hline Very comfortable & $6(7.2)$ & $2(3.0)$ & \\
\hline What is child's swim ability? (\%) & & & 0.41 \\
\hline Novice & $78(94.0)$ & $59(89.4)$ & \\
\hline Intermediary & $5(6.0)$ & $6(9.1)$ & \\
\hline Advanced & $0(0.0)$ & $1(1.5)$ & \\
\hline $\begin{array}{l}\text { Sibling also participated in intervention } \\
(\%)\end{array}$ & $59(71.1)$ & $54(81.8)$ & 0.18 \\
\hline Baseline skill (mean (SD)) & $13.00(9.61)$ & $12.21(8.98)$ & 0.61 \\
\hline Parent has fear of water (\%) & $40(48.2)$ & 42 (63.6) & 0.09 \\
\hline $\begin{array}{l}\text { Parent has had formal swim lessons } \\
(\%)\end{array}$ & $7(8.4)$ & $2(3.0)$ & 0.30 \\
\hline $\begin{array}{l}\text { Parent has skill and confidence to } \\
\text { swim } 25 \text { yards unassisted (\%) }\end{array}$ & $15(18.1)$ & $6(9.1)$ & 0.18 \\
\hline \multicolumn{3}{|c|}{$\begin{array}{l}\text { Parent has perceived skill and confidence in rescuing someone } \\
\text { drowning (\%) }\end{array}$} & 0.44 \\
\hline Not at all & $46(55.4)$ & $45(68.2)$ & \\
\hline Very little & $6(7.2)$ & $5(7.6)$ & \\
\hline Neutral & $15(18.1)$ & $10(15.2)$ & \\
\hline Somewhat & $3(3.6)$ & $1(1.5)$ & \\
\hline Comfortable & $13(15.7)$ & $5(7.6)$ & \\
\hline Recruitment site & & & 0.54 \\
\hline After school programme & $8(9.6)$ & $12(18.2)$ & \\
\hline Community centre & $25(30.1)$ & $19(28.8)$ & \\
\hline School 1 & $11(13.3)$ & $11(16.7)$ & \\
\hline School 2 & $6(7.2)$ & $2(3.0)$ & \\
\hline School 3 & $33(39.8)$ & $22(33.3)$ & \\
\hline Distance to intervention (mean (SD)) & $0.97(0.64)$ & $1.03(0.68)$ & 0.57 \\
\hline
\end{tabular}


community programme, customised for children ages 3-14, was offered as an intervention to children whose parents agreed to their participation. Children were assigned to small-group swim classes at different levels, based on their performance during a 15 min in-water test administered by a qualified tester. Parents were allowed to register their children for once, twice or three times per week swimming lessons, for a maximum of 20 lessons per child. The children were grouped by both level of ability and age (3-5, 6-9 and 10-14). Classes were co-ed, with the most recent skill test determining the assigned level for a subsequent 2-week sessions. All swimming lessons were conducted in English. The tester was the same for all children and for all follow-ups. The programme followed a standard curriculum focusing on water safety, floatation and endurance, at five levels of increasing skill acquisition (see online supplementary appendix A). During the last lesson of each session, the tester assessed each child's current skills and allowed advancement if all skills for a given level were performed to satisfaction. Whenever a child advanced to the next level, a ribbon was awarded, as an incentive for continuing participation.

\section{Training}

We trained two health educators, one tester, six swim teachers and one data entry person in the selected standard curriculum and related procedures. The health educators-who also served as the translators from English to Spanish of the parent safety curriculum-completed a 4-hour interactive training session, to help them master the content, field questions and facilitate discussion. The tester was instructed on how to score, while the data entry person was instructed on how to input the data, so as to minimise inconsistencies. Experienced teachers were recruited from another programme, a learn-to-swim programme based on a training model that was roughly equivalent (in terms of flotation and endurance) to the one used for our study but did not include the water safety component. All teachers underwent a 3-hour training relating to the swim skill test instrument and the water safety items, in addition to participating in a discussion about the importance of holistic approach to teaching, rather than 'teaching to the test'.

\section{Swim skill test instrument}

We incorporated 'best practices' with regard to swim evaluation tools, ${ }^{21}$ designing an assessment tool for our purposes. This assessment tool, while not formally evaluated for reliability and criterion validity, implemented a standardised approach to baseline testing and assessment of progress. The swim skill test instrument-covering basic and intermediate skills relating to water safety, floatation and endurance-was comprised of five levels, with 75 individual items which were completed by an observer to document whether or not a child could complete each skill within a level (see online supplementary appendix A). Face and content validity ${ }^{22}$ were assessed by an advisory panel comprised of members from the CDC, USA Swimming and National Drowning Prevention Alliance, as well as a water safety litigation specialist.

\section{Data collection}

Individual, family and community characteristics (independent variables shown in table 1) were recorded by means of child and parent surveys at the time of the parent health education intervention. Children's attendance at swimming lessons was monitored and recorded daily by the health educators using a computer attendance software. Swimming skill acquisition was assessed by the tester (independent from the class teacher) and recorded on the fourth lesson during each session. Data were promptly entered by the data entry person, located in a room adjacent to the pool.

\section{Main outcome}

The key outcome was change in a child's swimming ability. Specifically, skill acquisition was measured using the swim skill test instrument, by a single tester (completing both the baseline and follow-up tests), with all children having the opportunity to demonstrate their skills to the tester on the final day of each session. Change in swimming ability was represented as a computed score derived from a child's change in skills, from the time of baseline testing to the time of the final swimming skill assessment. The change in score was calculated by subtracting the baseline score from the final swimming skill assessment score.

\section{Statistical analysis}

Analysis proceeded in five steps. First, we compared baseline characteristics between male and female study participants using $t$ and $\chi^{2}$ testing. Second, we used the statistical technique known as bootstrapping, to develop unadjusted overall, age and gender-stratified interval estimates of the average number of skills acquired during the intervention. Third, we employed analysis of variance to assess the simultaneous impact of age, gender and number of swimming lessons on skill acquisition change, without additional covariate adjustment, while accounting for multiple comparisons by using Tukey's honest significant differences (HSD) procedure. Then, we employed analysis of covariance (ANCOVA) to determine factor-factor interaction. All calculations were performed using the $\mathrm{R}$ programming language (V.3.3.0, 2016) and the MICE (Multivariate Imputation via Chained Equations) library for multiple imputation of missing independent variable data ( $\mathrm{R}$ Core Team. R: A language and environment for statistical computing. R Foundation for Statistical Computing, Vienna, Austria. 2016. https://www. R-project.org/.).

Finally, in our secondary analysis, we compared outcomes of children with low exposure with those with high exposure, while accounting for any overt selection bias, relying on propensity score matching using calipres. ${ }^{23}$ Low and high exposure were determined by the distribution of swimming lesson variable, lower one-third cut-offs, trade-off in power and community best practice guidelines of minimum 10 swim lessons. We used mixed-effect models to estimate differences in skill acquisition between matched samples.

\section{RESULTS}

\section{Participants}

Among the 395 children who were recruited for the intervention, 149 (37.7\%) met all of the inclusion criteria (see figure 2). Participating boys $(n=66)$ and girls $(n=83)$ were similar across most baseline characteristics (see table 1 ).

\section{Skill acquisition by gender and age}

Average-unadjusted skill acquisition improvement was 12.3 (95\% CI ranging from 10.0 to 13.0 ), obtained through bootstrapping. Skill acquisition improvement was slightly higher among girls $(13.4$, 95\% CI 11.2 to 16.0$)$ compared with boys (11.1, 95\% CI 8.9 to 13.3$)$, who had an equivalent number of swimming lessons.

\section{Interaction}

Overall, the average participant attended 9.2 swimming lessons (ranging from 1 to 20, with a median of 9.5, and IQR 6-13). 
Figure 2 Conceptual model.

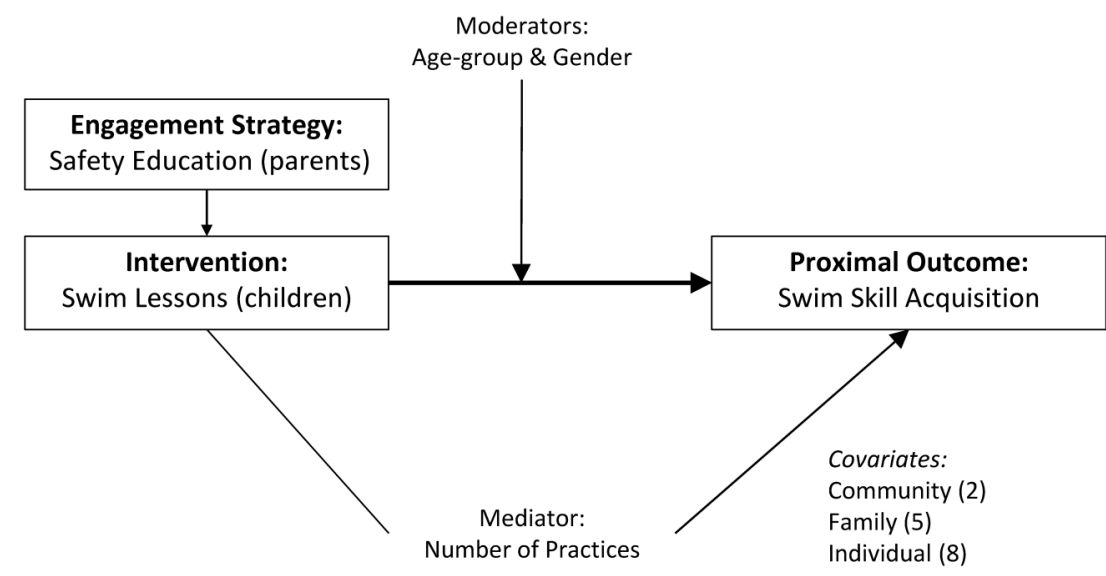

Skill acquisition improvement was notably higher among the oldest age group (10-14), especially among girls (20.8, 15.0, 26.7). We tested for variations of skill acquisition by age group, gender and number of swimming lessons. To explore whether meaningful differences existed between gender and age groups, we first classified the number of swimming lessons into three groups: low intensity as 7 or fewer swimming lessons, medium intensity as 8-9 swimming lessons and high intensity as 10 or more. We found a significant difference in skill acquisition improvement between the low and high-intensity groups, in the expected direction (point estimate: 10.8, 95\% CI 6.9 to 14.7), but no statistical difference between the low and medium intensity groups (difference of $3.6,95 \%$ CI -1.9 to 9.0). Figure 3 shows the three-way interaction in terms of gender, age group and number of swimming lessons. Girls and boys responded similarly to increasing numbers of swimming lessons, with notable differences by age group. Age group and gender interaction were neither significant nor substantial. For girls 10-14, however, swimming lesson interaction was significant, adjusting

\section{Boys}

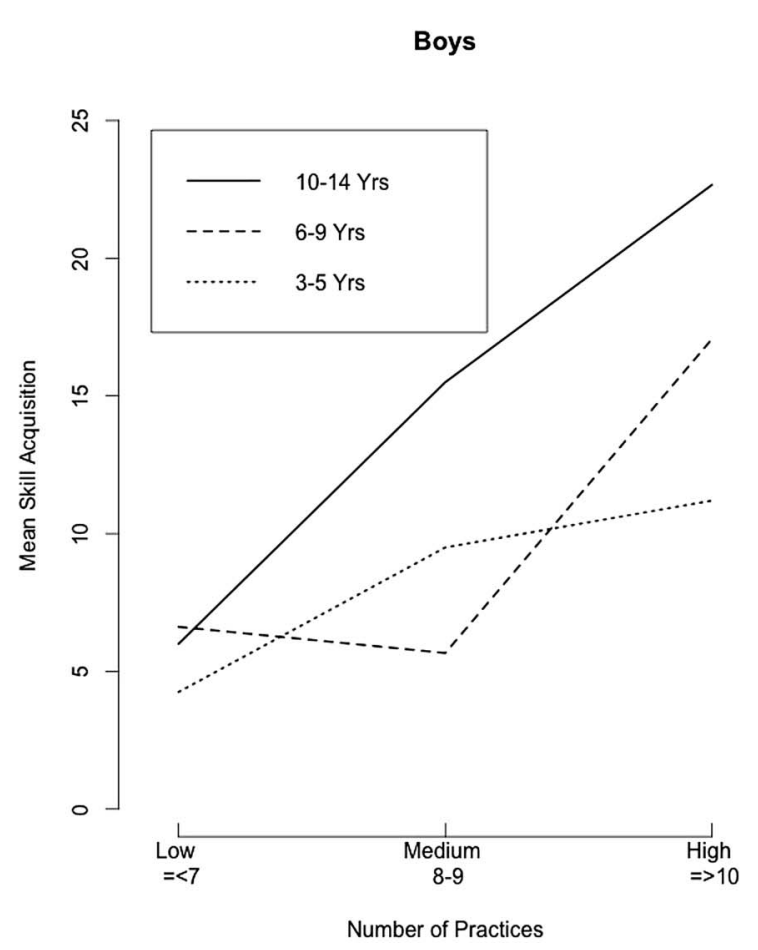

for multiple comparison with Tukey HSD $(p=0.04)$. Taking into account the two moderators (age and gender), ${ }^{24}$ the mediator (number of swimming lessons) and an interaction term ${ }^{25}$ (with age group and swimming lessons), the adjusted effect of this intervention was found to be $6.8(1.6,12.0)$. This indicates that this intervention's effect differs by age, gender and number of swimming lessons, and the effects are 'superadditive' or 'synergistic' among girls ages 10-14.

\section{Propensity score analysis}

We compared participants with low and median exposure (9 or fewer swimming lessons) with those with high exposure (10 or more swimming lessons), as a means of overcoming a major limitation of observational study design: selection bias. Members of both the low-median and high-exposure groups were culled to achieve commonality in terms of a comprehensive set of 15 baseline characteristics (eg, age, gender and preexisting swimming skills), so that each matched member of the low group had an equivalent member in the high group (ie, a

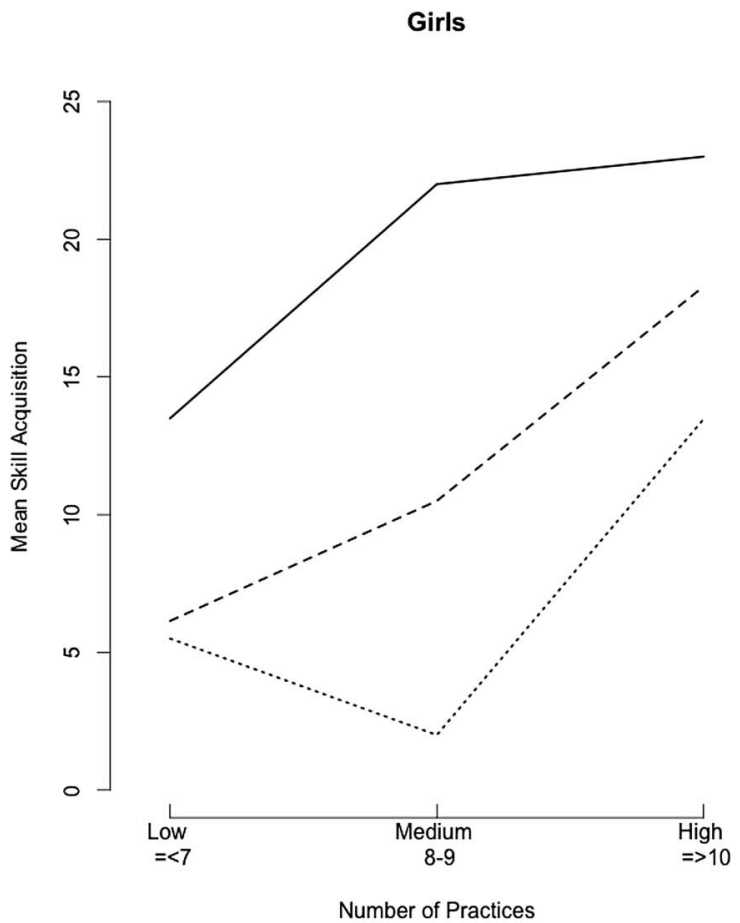

Figure 3 Three-way interaction plots. 
one-to-one correspondence). Prior to matching, we observed major differences with regard to some of the characteristics in the full sample of 149. After matching, none of the baseline characteristics differed between the two groups, with the population sample subsequently narrowed down to 104 . Children in the matched sample who participated in 10 or more swimming lessons gained on average of 8.2 more skills $(4.8,11.8)$, compared with children with 9 or fewer swimming lessons. The average swimming lesson effect obtained through propensity score analysis was 24\% lower than the unadjusted swimming lesson effect (see table 2), representing both a more conservative and more accurate reflection of the mediating effect of swimming lessons. ${ }^{24}$

\section{DISCUSSION}

This study sought to estimate the effect of swimming lessons on skill acquisition improvement, critical for reducing the incidence of drowning and also for reducing the additional rate at which this occurs among certain populations. We found that for this intervention, tailored to the needs of Latino immigrant children ages 3-14, swimming lessons was the key predictor of skill acquisition improvement, with neither age nor gender significant, except among girls ages 10-14, who outperformed all categories of their peers.

Current research in drowning prevention, with few exceptions, has been primarily limited to retrospective studies and cross-sectional surveys. Asher et $a l^{26}$ compared performance among preschool children with 2 vs 3 months of training in swimming and water safety, finding that 3 months of practice, as opposed to 2, resulted in superior outcomes. An earlier study ${ }^{27}$ involved a non-randomised control experiment, reporting a similar swimming lesson effect. Most recently, Petrass and Blitvich $^{28}$ found statistically significant effect of a 12-week swim intervention administered to 135 young adults. None of the above-mentioned articles reported intervention effect measures, neither overall nor stratified by age and gender.

The result that the older Latina girls, ages 10-14, performed significantly better than members of the other categories was unexpected. As this was an observational study of children enrolled in a community programme and not a randomised intervention, it could be that the group effect just mentioned can be explained by a positive confounder. ${ }^{25}$ Maybe older girls were more motivated than members of other groups, taking the endeavour more seriously, practising their skills in apartment pool complexes outside the context of their formal lessons and thereby accelerating the pace of their learning. As we did not identify or measure potential confounders, we instead undertook propensity analysis.

To our knowledge, this is the first observational study relating to injury prevention to employ propensity score analysis, so as to estimate an unbiased effect. ${ }^{29}$ Our propensity analysis aimed at addressing possible underlying confounders that could explain both the unadjusted and adjusted effects, had we considered them at the beginning. Propensity score analysis is a method for assessing an observational study as if it had been designed as a randomised clinical trial. We compared a matched subset of participants, children with 9 or fewer swimming lessons, with children with 10 or more swimming lessons. Members of the lowmedium exposure groups experienced only a marginal effect, specifically among children 9 years and younger, with regard to skill acquisition, as shown in figure 3. It was not until a threshold of 10 or more lessons that children's rates of learning accelerated. The overall, bias-adjusted effect of swimming lessons of this intervention-8.2 (with a range of 4.8 to 11.8 ) - reflects the difference in learning between the two matched groups.

Our study advances intervention research through the use of (1) an innovative recruitment strategy, (2) the combining of practice-based evidence with evidence-based practice in intervention design and (3) the employment of novel statistical methods. At the same time, several limitations of this study should be acknowledged. First, our instrument has not yet undergone testing for formal reliability and criterion validity. We were thus limited to building on practice-based evidence, followed by face and content validity. Also, of the 312 children who met the inclusion criteria, there was a significant loss $(52 \%)$ in terms of follow-up. Participants and non-participants, however, were similar with regard to most baseline characteristics. We also did not check the tester's accuracy of scoring following training, introducing possible measurement error. Lastly, swimming instruction was delivered in English, a clear limitation, particularly among the youngest age group, as English is often not formally introduced to Latino immigrants in this community until the first year of elementary school.

While our secondary analysis corrected for bias introduced by our non-randomised design, a pragmatic randomised cluster clinical trial relying on a fully validated swim skill test instrument is warranted. Such a study will allow generalisability of results. Such a design could be of critical value in assessing the cost-effectiveness of the intervention and subsequent policy, should the USA follow suit with other developed nations in enforcing the inclusion of swimming within the physical activity curricula in elementary and middle schools. Finally, the dynamics of swim skill retention are characterised by substantial disagreement. Retention of swimming skills, year by year, represents a productive avenue for further research in the area of injury prevention, for scientists committed to reduce the incidence of morbidity and mortality in water.

\section{CONCLUSION}

This intervention study contributes to the knowledge of intervention effectiveness in injury prevention, primarily through the finding that number of swimming lessons-rather than gender or age group-represents the major contributing factor to swim skill acquisition. A minimum threshold of 10 swimming lessons within an 8 -week interval is recommended.

Table 2 Overall, adjusted and bias-adjusted intervention effect

\begin{tabular}{|c|c|c|c|c|c|c|c|c|c|}
\hline \multirow[b]{2}{*}{ Approach } & \multicolumn{4}{|c|}{ Intervention effect } & \multirow[b]{2}{*}{ Approach } & \multicolumn{4}{|c|}{ Swimming lesson effect } \\
\hline & $\mathbf{n}$ & $\begin{array}{l}\text { Point } \\
\text { estimate }\end{array}$ & $\begin{array}{l}\text { Lower } \\
95 \% \mathrm{Cl}\end{array}$ & $\begin{array}{l}\text { Upper } \\
95 \% \mathrm{Cl}\end{array}$ & & $\mathbf{n}$ & $\begin{array}{l}\text { Point } \\
\text { estimate }\end{array}$ & $\begin{array}{l}\text { Lower } \\
95 \% \mathrm{Cl}\end{array}$ & $\begin{array}{l}\text { Upper } \\
95 \% \mathrm{Cl}\end{array}$ \\
\hline Unadjusted & 149 & 12.3 & 10.7 & 14.1 & Analysis of variance with Tukey HSD & 127 & 10.8 & 6.9 & 14.7 \\
\hline Adjusted (sex, age, swimming lesson) & 149 & 6.8 & 1.6 & 12.0 & Propensity matching without replacement & 104 & 8.2 & 4.8 & 11.8 \\
\hline
\end{tabular}




\section{What is already known on the subject}

- Drowning is the second leading cause of unintentional injury resulting in death among children ages 1-14.

- African Americans and Latinos are at greater risk of drowning than whites.

- Boys are twice as likely to drown as girls.

- Swimming lessons may decrease the risk of drowning for Latino children.

\section{What this study adds}

- An 8-week intervention has been found to be effective for improving swimming skill acquisition among Latino children, ages 3-14.

- Swimming lessons is a far stronger correlate of skill acquisition than age or gender.

- Intervention research may be advanced through the use of the unique methodology involving a combination of (1) an innovative recruitment strategy, (2) the combining of practice-based evidence with evidence-based practice in intervention design and (3) the employment of novel statistical methods.

Acknowledgements The authors would like to thank the Hoover/Abilities United staff for public health service; Chris Beth at Redwood City Parks, Recreation and Community Services for project vision and follow-through; Ayona Chatterjee, PhD at CSU East Bay for study design advice; Mark Schluchter, PhD, at CWRU for guidance with next steps, and the contributions of the two reviewers.

Contributors RHO envisioned, designed the study and led analysis and write-up. SF provided insight in analysis, write-up, editing and revision. TL provided guidance in analysis, edited drafts and the statistical programme.

Funding Redwood City, Park, Recreation and Community Services; Newman Foundation.

Competing interests None declared.

Patient consent Obtained.

Ethics approval Abilities United.

Provenance and peer review Not commissioned; externally peer reviewed.

Data sharing statement The entire dataset and code is available to researchers attempting to replicate this study in parts or in whole.

\section{REFERENCES}

1 Centers for Disease Control and Prevention (CDC). Drowning - United States, 2005-2009. MMWR Morb Mortal Wkly Rep 2012;61:344-7.

2 Centers for Disease Control and Prevention (CDC). Vital signs: unintentional injury deaths among persons aged 0-19 years-United States, 2000-2009. MMWR Morb Mortal Wkly Rep 2012;61:270-6.
3 Agócs MM, Trent RB, Russell DM. Activities associated with drownings in Imperial County, CA, 1980-90: implications for prevention. Public Health Rep 1994;109:290-5.

4 Warneke CL, Cooper SP. Child and adolescent drownings in Harris County, Texas, 1983 through 1990. Am J Public Health 1994;84:593-8.

5 Quan L, Cummings P. Characteristics of drowning by different age groups. Inj Prev 2003;9:163-8.

6 Brenner RA. Prevention of drowning in infants, children, and adolescents. Pediatrics 2003;112:440-5

7 Howland J, Hingson R, Mangione TW, et al. Why are most drowning victims men? Sex differences in aquatic skills and behaviors. Am J Public Health 1996;86:93-6.

8 Saluja G, Brenner RA, Trumble AC, et al. Swimming pool drownings among US residents aged 5-24 years: understanding racial/ethnic disparities. Am J Public Health 2006;96:728-33.

9 Peden MM, McGee K. The epidemiology of drowning worldwide. Inj Control Saf Promot 2003;10:195-9.

10 Irwin CC, Irwin RL, Ryan TD, et al. Urban minority youth swimming (in)ability in the United States and associated demographic characteristics: toward a drowning prevention plan. Inj Prev 2009;15:234-9.

11 Gilchrist J, Parker EM. Racial/ethnic disparities in fatal unintentional drowning among persons aged $\leq 29$ years-United States, 1999-2010. MMWR Morb Mortal Wkly Rep 2014;63:421-6.

12 Healthy People 2020. Injury and Violence Prevention. 2010. https://www. healthypeople.gov/2020/topics-objectives/topic/injury-and-violence-prevention/ objectives (accessed Apr 2017).

13 Brenner RA. Childhood drowning is a global concern. BMJ 2002;324:1049-51.

14 Brenner RA, Taneja GS, Haynie DL, et al. Association between swimming lessons and drowning in childhood: a case-control study. Arch Pediatr Adolesc Med 2009;136:203-10.

15 World Health Organization. Facts about injuries, drowning. Geneva: World Health Organization, 2003

16 Lawson PJ, Flocke SA. Teachable moments for health behavior change: a concept analysis. Patient Educ Couns 2009;76:25-30.

17 Smith GS. Drowning prevention in children: the need for new strategies. Inj Prev 1995;1:216-17

18 Johnson SB, Jones VC. Adolescent development and risk of injury: using developmental science to improve interventions. Inj Prev 2011;17:50-4.

19 Rosenstock IM. The health belief model and preventive health behavior. Health Educ Behav 1974;2:354-86.

20 Bronfenbrenner U. Toward an experimental ecology of human development. Am Psychol 1977;32:513.

21 De Martelaer K, Soons B. Development and validation of a water safety test for children in three age groups. Sci Sports 2014;29:S46-7.

22 Cook DA, Beckman TJ. Current concepts in validity and reliability for psychometric instruments: theory and application. Am J Med 2006;119:166.e7-16.

23 Rubin DB. Estimating causal effects of treatments in randomized and nonrandomized studies. J Educ Psychol 1974;66:688-701.

24 Rothman KJ, Greenland S, Walker AM. Concepts of interaction. Am J Epidemiol 1980;112:467-70.

25 Bauman AE, Sallis JF, Dzewaltowski DA, et al. Toward a better understanding of the influences on physical activity: the role of determinants, correlates, causal variables, mediators, moderators, and confounders. Am J Prev Med 2002; 23:5-14.

26 Asher KN, Rivara FP, Felix D, et al. Water safety training as a potential means of reducing risk of young children's drowning. Inj Prev 1995;1:228-33.

27 Erbaugh SJ. Effects of aquatic training on swimming skill development of preschool children. Percept Mot Skills 1986;62:439-46.

28 Petrass LA, Blitvich JD. Preventing adolescent drowning: understanding water safety knowledge, attitudes and swimming ability. The effect of a short water safety intervention. Accid Anal Prev 2014;70:188-94.

29 Rubin DB. For objective causal inference, design trumps analysis. Ann App/ Stat 2008; $2: 808-40$ 